\title{
Simulation of at-sensor radiance over land for proposed thermal channels of Imager payload onboard INSAT-3D satellite using MODTRAN model
}

\author{
M R Pandya ${ }^{1, *}$, D B Shah ${ }^{2}$, H J TRIVEdi ${ }^{2}$ and S Panigrahy ${ }^{1}$ \\ ${ }^{1}$ Space Applications Centre, Indian Space Research Organisation, Ahmedabad 380 015, India. \\ ${ }^{2}$ N. V. Patel College of Pure and Applied Sciences, Vallabh Vidyanagar, India. \\ *email: mrpandya@sac.isro.gov.in
}

\begin{abstract}
INSAT-3D is the new generation Indian satellite designed for improved Earth observations through two payloads - Imager and Sounder. Study was conducted with an aim of simulating satellite level signal over land in the infrared channels of the Imager payload using a radiative transfer model MODTRAN. Satellite level at-sensor radiance corresponding to all four infrared channels of INSAT-3D Imager payload is obtained using MODTRAN and sensitivity of at-sensor radiance was inferred as a function of input parameters namely, surface temperature, emissivity, view angle and atmospheric water vapour, which is helpful in understanding the signal simulation scheme needed for retrieving a very critical parameter namely, land surface temperature.
\end{abstract}

\section{Introduction}

INSAT-3D is the new generation Indian satellite planned by the Indian Space Research Organization (ISRO) for Earth observations. INSAT-3D satellite will provide enhanced measurements of atmosphere, ocean and land surfaces through two payloads namely, Imager and Sounder from the geostationary orbit. The Imager payload will be the first Indian sensor onboard geostationary platform providing images at every half an hour in six spectral channels covering visible (VIS: $0.55-0.75 \mu \mathrm{m}$ ), shortwave infrared (SWIR: 1.55-1.70 $\mu \mathrm{m}$ ), midinfrared (MIR: 3.8-4.0 $\mu \mathrm{m}$ ), water vapour infrared (WVIR: $6.5-7.1 \mu \mathrm{m}$ ) and thermal infrared (TIR1: $10.3-11.3 \mu \mathrm{m}$ and TIR2: $11.5-12.5 \mu \mathrm{m}$ ) range of electromagnetic spectrum. The spatial resolution of the Imager at nadir is $1 \mathrm{~km}$ for VIS and SWIR channels; $4 \mathrm{~km}$ for MIR, TIR1 and TIR2 channels; and $8 \mathrm{~km}$ for WVIR channel. The major sensor specifications of the Imager payload are summarized in tables 1 and 2 (CDR 2009). With the ability of multispectral imaging and frequent coverage of one third of the globe, this payload opens up the newer opportunity for various applications. Before using the observations from the infrared channels of Imager payload over the land especially for inferring land surface temperature (LST), radiance emitted from the land surfaces must be simulated and understood pertaining to various land and atmospheric characteristics. A theoretical modelling exercise is carried out with an aim to simulate the at-sensor radiance for the proposed thermal channels of the Imager payload of INSAT$3 \mathrm{D}$ satellite over the land surfaces using a radiative transfer model (RTM).

\section{Theory}

\subsection{Equation of at-sensor radiance}

The sensor viewing the Earth's surface receives radiance from three sources: the surface, the

Keywords. Earth observation; imager; INSAT-3D; land surface; MODTRAN; simulation; thermal infrared. 
Table 1. General specifications of Imager payload (CDR 2009).

\begin{tabular}{ll}
\hline Platform & INSAT-3D, Geostationary orbit \\
Spectral channel & Six $($ Spectral region: visible, SWIR, MIR, WVIR, TIR1, TIR2) \\
Field of regard (coverage) & $24^{\circ} \mathrm{E}-\mathrm{W} \times 21^{\circ} \mathrm{N}-\mathrm{S}$ \\
Scan modes & Full frame and programmable sector modes \\
Imaging periodicity & Full frame mode: $\leq 30$ minutes \\
& Programmable mode: $1.1 \mathrm{~s}$ per scan line \\
Signal quantization & 10 bits/sample \\
\hline
\end{tabular}

Table 2. Spectral and spatial specifications of Imager payload onboard INSAT-3D satellite (CDR 2009).

\begin{tabular}{lcc}
\hline Channel & $\begin{array}{c}\text { Range of the } \\
\text { spectral channel }\end{array}$ & $\begin{array}{c}\text { Spatial resolution } \\
\text { (at nadir) }\end{array}$ \\
\hline VIS & $0.55-0.75 \mu \mathrm{m}$ & $1 \mathrm{~km}$ \\
SWIR & $1.55-1.70 \mu \mathrm{m}$ & $1 \mathrm{~km}$ \\
MIR & $3.8-4.0 \mu \mathrm{m}$ & $4 \mathrm{~km}$ \\
WVIR & $6.5-7.1 \mu \mathrm{m}$ & $8 \mathrm{~km}$ \\
TIR1 & $10.3-11.3 \mu \mathrm{m}$ & $4 \mathrm{~km}$ \\
TIR2 & $11.5-12.5 \mu \mathrm{m}$ & $4 \mathrm{~km}$ \\
\hline
\end{tabular}

atmosphere and the Sun. Therefore, the at-sensor radiance is a combination of three terms:

- the surface-emitted radiance after being attenuated by the atmosphere,

- the upwelling sky radiance emitted by the atmosphere towards the sensor, and

- the downwelling radiation reaching the sensor after being reflected from the Earth's surface.

$$
\begin{aligned}
L_{i}\left(T_{i}\right)= & \varepsilon_{i} \cdot B_{i}\left(T_{s}\right) \cdot \tau_{i}+L_{i}^{\uparrow} \\
& +\left(1-\varepsilon_{i}\right) \cdot L_{\mathrm{DWR}} \cdot \tau_{i},
\end{aligned}
$$

where $L_{i}$ is the radiance measured by the sensor, $T_{i}$ is the at-sensor brightness temperature, $\tau_{i}$ is the atmospheric transmittance, $L_{i}^{\uparrow}$ is the upwelling path radiance, $\varepsilon_{i}$ is the surface emissivity, $B_{i}\left(T_{s}\right)$ is Planck radiance at surface temperature $T_{s}$ and $L_{\text {DWR }}$ is the downwelling sky irradiance at the Earth's surface. Here all the quantities refer to a spectral integration over the bandwidth of channel $i$ and depend on the view zenith angle. The third term of equation (1) can be neglected since the infrared channels of the Imager payload are such that the reflected and scattered radiance from the Sun is negligible when compared with the radiance emitted by the surface and atmosphere (an exception is 3.8-4.0 $\mu \mathrm{m}$ channel in which the total signal can have contributions from the Sun, however this channel is not used normally in the LST retrieval). Understanding and modelling the atmospheric contribution is a critical task in order to compute the total radiance reaching the sensor, which is discussed in the following sections.

\subsection{Atmospheric contribution}

Water vapour is the prime atmospheric constituent affecting the atmospheric behaviour in the TIR region, while aerosol absorption and scattering are negligible and generally ignored in this region. Since the water vapour is poorly mixed in the atmosphere and is having variations on short time scales, it is considered to be a cardinal variable influencing the atmospheric transmittance.

However, ozone $\left(\mathrm{O}_{3}\right)$ and carbon dioxide $\left(\mathrm{CO}_{2}\right)$ are evenly distributed in the space and they also influence atmospheric transmittance but to a lesser extent than that is caused by the water vapour. Therefore, frequent information about the state of the atmosphere, specifically, the temperature and water vapour profiles with different altitude is needed for the radiance measurements. Figure 1 shows a well-known profile of transmittance spectrum for tropical atmosphere with croplands surface having a temperature of $300 \mathrm{~K}$ in the respective range of wavelengths.

The places of major atmospheric absorption due to the presence of different gases are indicated in the figure. An increasing tendency with strong absorption is observed in the range of $8-9 \mu \mathrm{m}$ which is due to the atmospheric water vapour, $\mathrm{N}_{2} \mathrm{O}, \mathrm{CO}_{2}$ and $\mathrm{CH}_{4}$. Strong absorption centered at $9.66 \mu \mathrm{m}$ is observed in the range $9-10 \mu \mathrm{m}$ which is due to $\mathrm{O}_{3}$. In the range 10-12 $\mu \mathrm{m}$, a slightly descending tendency with high atmospheric transmissivity values are obtained having absorption peaks weaker than that of $8-9 \mu \mathrm{m}$ regions which is entirely due to the water vapour. So this region (atmospheric window) is mostly used in thermal infrared remote sensing. In the region of $12-13 \mu \mathrm{m}$, the transmittance is lower than that is obtained in $10-12 \mu \mathrm{m}$ region and the absorption is mainly due to atmospheric water vapour content. Finally in the range 13$14 \mu \mathrm{m}$ region, a strong absorption is observed due to $\mathrm{CO}_{2}$.

\section{The MODTRAN model}

The satellite level signal in the infrared channels of the Imager payload was simulated using an 


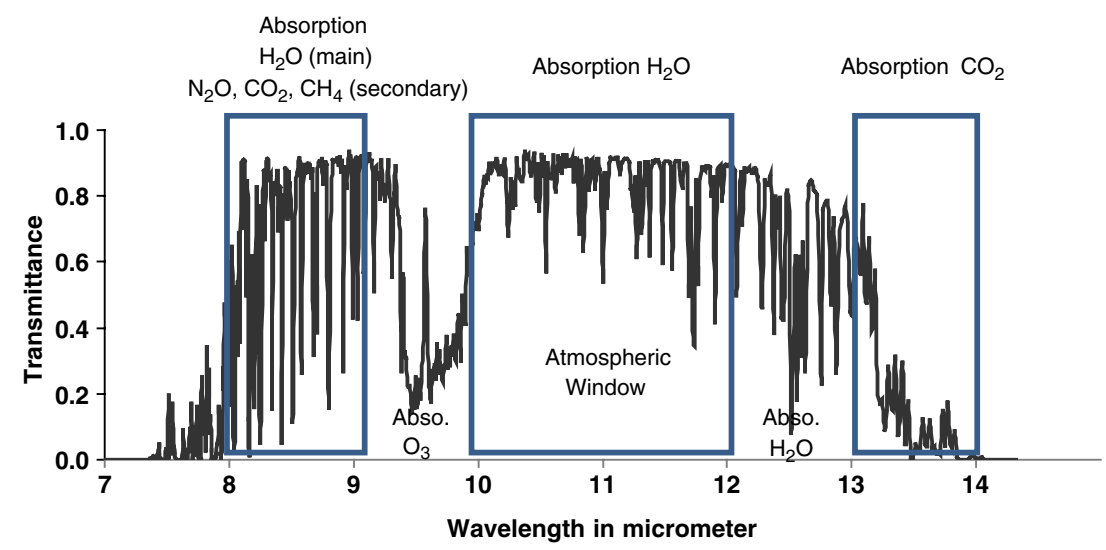

Figure 1. Typical graph of atmospheric transmittance in infrared region computed using the MODTRAN model for the tropical atmosphere, surface temperature of $300 \mathrm{~K}$ and atmospheric water vapour $1.5 \mathrm{~g} / \mathrm{cm}^{2}$ showing some of the absorption windows of gases along with the atmospheric windows useful in surface temperature retrieval.

RTM-MODTRAN (MODerate spectral resolution atmospheric TRANsmittance) version 4.0. MODTRAN (developed by the Air Force Research Laboratory, USA) was selected for the study because this RTM has been available publicly for long and its heritage traces back to LOWTRAN. MODTRAN includes all the functional capabilities of Low Resolution Transmittance code (LOWTRAN 7.0) (Kneizys et al 1988). It uses a more accurate and higher resolution molecular band model with $2 \mathrm{~cm}^{-1}$ spectral resolution based on the atlas of high resolution molecular spectroscopic data (HITRAN) (Rothman et al 1992). It is a widely used and validated model for variety of remote sensing analyses and applications across the globe. With its spectral resolution capability of $2 \mathrm{~cm}^{-1}$, this narrowband model can perform calculations as accurate as line-by-line code with less input requirements as discussed by Lacis and Oinas (1991) and Liang (2004). They have shown that using two narrow spectral ranges of $\mathrm{H}_{2} \mathrm{O}$ and $\mathrm{CO}_{2}$ (for a resolution of $10 \mathrm{~cm}^{-1}$, and for total gas pressures above $0.1 \mathrm{~atm}$ ), the correlational accuracy can be improved to better than $1 \%$. It simulates at-sensor radiance and transmittance as a function of atmospheric inputs (model atmosphere, atmospheric column parameters, aerosol model, etc.), surface inputs (emissivity, temperature), viewing geometry and information on spectral channels. A set of radiosonde and satellite sounder profiles over tropical region from the SeeBor dataset (Borbas et al 2005) is selected for input in MODTRAN simulations. The atmospheric profiles covering the boundary layer atmospheric temperature from 260 to $315 \mathrm{~K}$ and water vapour concentration from 0.1 to $7 \mathrm{gm} / \mathrm{cm}^{2}$ have been selected in the present study. The attenuation due to atmosphere has been considered because of uniformly mixed gases, namely, $\mathrm{CO}_{2}, \mathrm{~N}_{2} \mathrm{O}, \mathrm{O}_{3}$ and $\mathrm{CH}_{4}$ along with the water vapour in the MODTRAN forward simulations. The contribution due to solar radiation in the MIR channel is not considered in the simulations.

\section{Simulations of satellite measurements}

In order to be more useful and acceptable, the radiative transfer simulations must encompass wide range of atmospheric and surface conditions. It can be achieved with the RTM MODTRAN 4.0. This is actually the major advantage of such numerical experiments with computer over the satellite or ground-based measurements. In the present study, we have simulated the at-sensor radiances in four IR spectral channels (MIR, WVIR, TIR1 and TIR2) of the Imager payload by varying the following six parameters in the respective spectral regions of interest:

(1) Temperature of the atmospheric lower boundary: The simulation for 20 atmospheric profiles over tropical region (SeeBor dataset) are carried out with the boundary layer temperature $\left(T_{\text {air }}\right)$, ranging from $270.9-308.7 \mathrm{~K}$. These profiles cover different geographical regions in and around India throughout the year.

(2) Atmospheric column water vapour: The water vapour (WV) values ranging from $0.1 \mathrm{~g} / \mathrm{cm}^{2}$ to near saturated level have been used through each atmospheric profile.

(3) Surface temperature: The land surface temperature (LST) ranging from $270-315 \mathrm{~K}$ has been taken keeping tropical region as the context.

(4) View zenith angle (VZA): 0 to 60 degrees.

(5) Spectral channels: Four IR channels MIR, WVIR, TIR1 and TIR 2 by considering squarewave response. 
Table 3. Band-averaged values of radiances in the channels of Imager sensor.

\begin{tabular}{|c|c|c|c|c|}
\hline \multirow[t]{2}{*}{$\begin{array}{l}\text { Spectral channel of } \\
\text { Imager sensor }\end{array}$} & \multicolumn{2}{|c|}{$\begin{array}{l}\text { At-sensor radiance } \\
\left(\mathrm{W} / \mathrm{m}^{2} / \mathrm{sr} / \mu \mathrm{m}\right)\end{array}$} & \multicolumn{2}{|c|}{$\begin{array}{l}\text { Path radiance } \\
\left(\mathrm{W} / \mathrm{m}^{2} / \mathrm{sr} / \mu \mathrm{m}\right)\end{array}$} \\
\hline & Min. & Max. & Min. & Max \\
\hline MIR & 0.11 & 1.62 & 0.02 & 0.06 \\
\hline WVIR & 0.97 & 3.61 & 0.97 & 3.42 \\
\hline TIR1 & 4.78 & 13.99 & 0.23 & 5.66 \\
\hline TIR2 & 4.72 & 12.44 & 0.21 & 6.18 \\
\hline
\end{tabular}

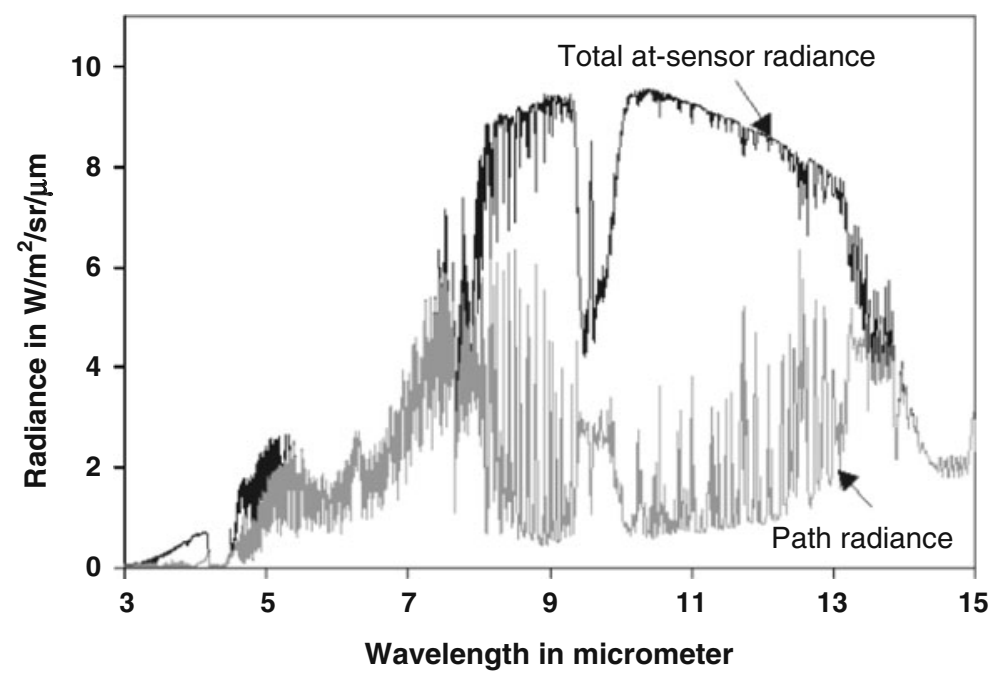

Figure 2. At-sensor radiance and path radiance as a function of wavelength (at nadir) shown for tropical atmosphere, with atmospheric WV of $1.5 \mathrm{~g} / \mathrm{cm}^{2}$ and surface temperature of $300 \mathrm{~K}$ computed with the MODTRAN.

(6) Land surface emissivity: From the standard International Geosphere Biosphere Program (IGBP) land cover types (available online) we have selected major 11 different land cover types (ocean water, snow, sand, crop, shrubs, grass, forest, savanna, wetland, urban) from the MODTRAN database.

\section{Results and discussion}

\subsection{Band-averaged values of transmittance and radiance}

The atmospheric transmission and at-sensor radiance values differ with respect to the variation in the atmospheric and land surface inputs in four different spectral channels. The atmospheric total transmittance for the four channels ranged from 0.53-0.89 for MIR, 0-0.004 for WVIR, 0.030.97 for TIR1 and 0.01-0.98 for TIR2 channels. The lower transmittance in each of the spectral bands was observed for the combination of inputs like: $T_{\text {air }}=308.7 \mathrm{~K}, \mathrm{LST}=315 \mathrm{~K}$, $\mathrm{WV}=7.5 \mathrm{~g} / \mathrm{cm}^{2}, \mathrm{VZA}=60^{\circ}$, while the higher transmittance was observed for $T_{\text {air }}=270.9 \mathrm{~K}$, $\mathrm{LST}=270 \mathrm{~K}, \mathrm{WV}=0.1 \mathrm{~g} / \mathrm{cm}^{2}, \mathrm{VZA}=0^{\circ}$. Total at-sensor radiance varied between 0.11 and $1.62 \mathrm{~W} / \mathrm{m}^{2} / \mathrm{sr} / \mu \mathrm{m}$ for MIR channel, 0.99 to $3.56 \mathrm{~W} / \mathrm{m}^{2} / \mathrm{sr} / \mu \mathrm{m}$ for WVIR channel, 4.78 to $13.99 \mathrm{~W} / \mathrm{m}^{2} / \mathrm{sr} / \mu \mathrm{m}$ for TIR1 channel and 4.72 to $12.44 \mathrm{~W} / \mathrm{m}^{2} / \mathrm{sr} / \mu \mathrm{m}$ for TIR2 channel. The band-averaged values of at-sensor radiance and path radiance are summarized in table 3. A typical graph of radiance versus wavelength is shown in figure 2 for an average atmospheric condition (WV of $1.5 \mathrm{~g} / \mathrm{cm}^{2}$, surface temperature of $300 \mathrm{~K}$ ) with two main components of the radiance (total at-sensor radiance and path radiance). The contribution from the path radiance is quite high in 5 to $7 \mu \mathrm{m}$, where significant atmosphere absorption takes place, while the path radiance is low in the atmospheric window region, i.e., in 10-12 $\mu \mathrm{m}$.

\subsection{Sensitivity of transmittance and radiance to model input}

The sensitivity of atmospheric transmittance and at-sensor radiances to the water vapour content in the atmosphere and view zenith angle were also inferred in the present study. Results of transmittance as a function of wavelength for varying WV are plotted in figure 3. Band positions of four thermal channels of the Imager payload are also 


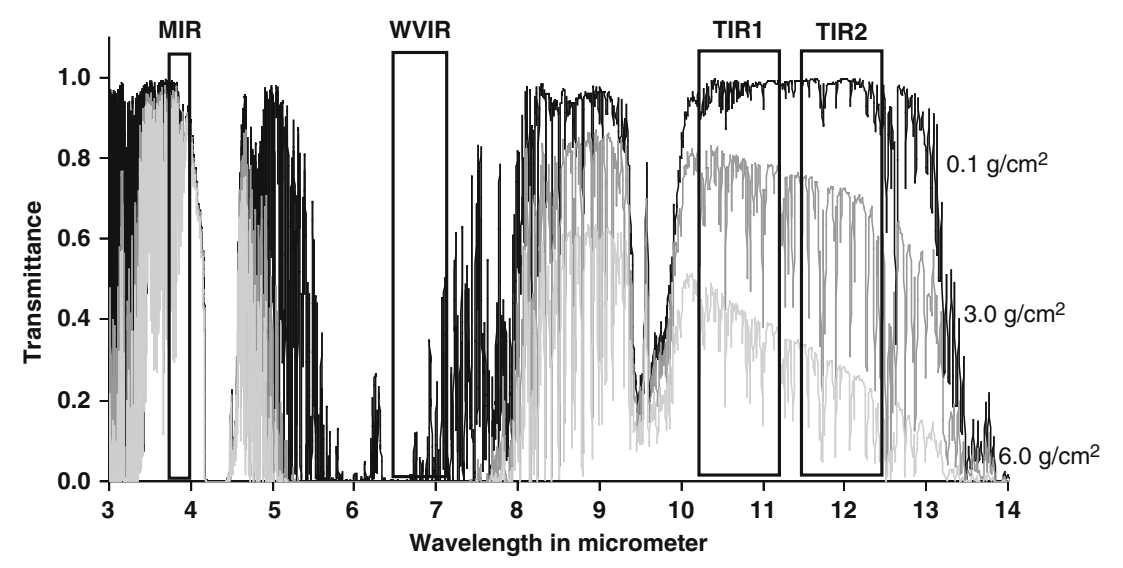

Figure 3. Atmospheric transmission computed for different atmospheric water vapour content (very less $-0.1 \mathrm{~g} / \mathrm{cm}^{2}$, moderate $-3.0 \mathrm{~g} / \mathrm{cm}^{2}$ and high $-6.0 \mathrm{~g} / \mathrm{cm}^{2}$ ) using the MODTRAN model for nadir observations with tropical atmosphere

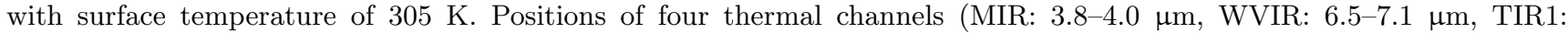
10.3-11.3 $\mu \mathrm{m}$ and TIR2: $11.5-12.5 \mu \mathrm{m})$ of the Imager payload are also shown in the graph.

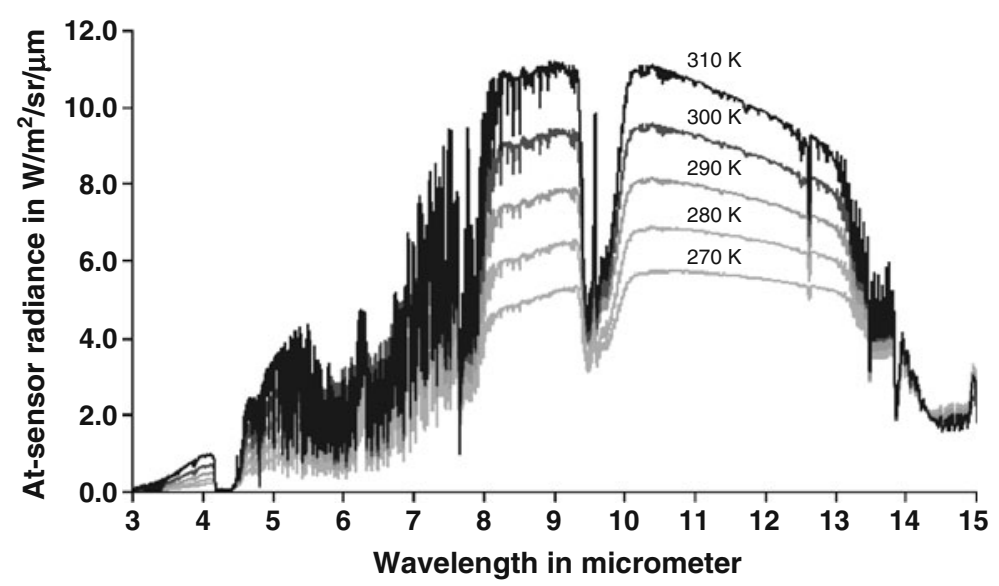

Figure 4. Sensitivity of the at-sensor radiance as a function of land surface temperature (270 to $310 \mathrm{~K})$ for nadir observations computed by the MODTRAN model for tropical atmospheric condition.

shown on the same curve. A significant reduction in transmission is observed with increasing amount of WV especially in 10-12 $\mu \mathrm{m}$ range. It reduces from 0.96 to 0.38 in TIR1 channel and 0.97 to 0.23 in TIR2 channel for the variation in the WV from 0.1 to $6.0 \mathrm{~g} / \mathrm{cm}^{2}$. Thus atmospheric WV considerably affects the transmittance and consequently modulates the total at-sensor radiance. At-sensor radiance showed a strong variation with the change in the LST. This is shown in figure 4, where a substantial increase in the radiance is seen with the increase in the LST. These variations are quite noticeable in the wavelength region of $8-13 \mu \mathrm{m}$, which is obvious since the peak radiance emitted from the Earth's surface lies in $10 \mu \mathrm{m}$. This is the region, which is used to derive LST from the satellite observations (Dash et al 2002).
The sensitivity of atmospheric parameters was also deduced as a function of the satellite view angle. Out of all the calculations, an example is shown in figure 5 , where transmittance is shown as a function of view zenith angle for varying water vapour concentration. The graph corresponds to the TIR1 channel for the tropical atmosphere and having surface temperature of $305 \mathrm{~K}$ (the MODTRAN calculations take into account the effects caused by atmospheric refraction and the curvature of the Earth).

It shows decreasing tendency in the transmittance as view zenith angle increases. The transmittance reduces from 0.96 to $0.92,0.88$ to $0.77,0.73$ to $0.53,0.55$ to $0.30,0.38$ to 0.14 and 0.24 to 0.05 for the water vapour of $0.1,1.5,3,4.5,6$ and $7.5 \mathrm{~g} / \mathrm{cm}^{2}$, respectively. The rate of reduction of transmittance 


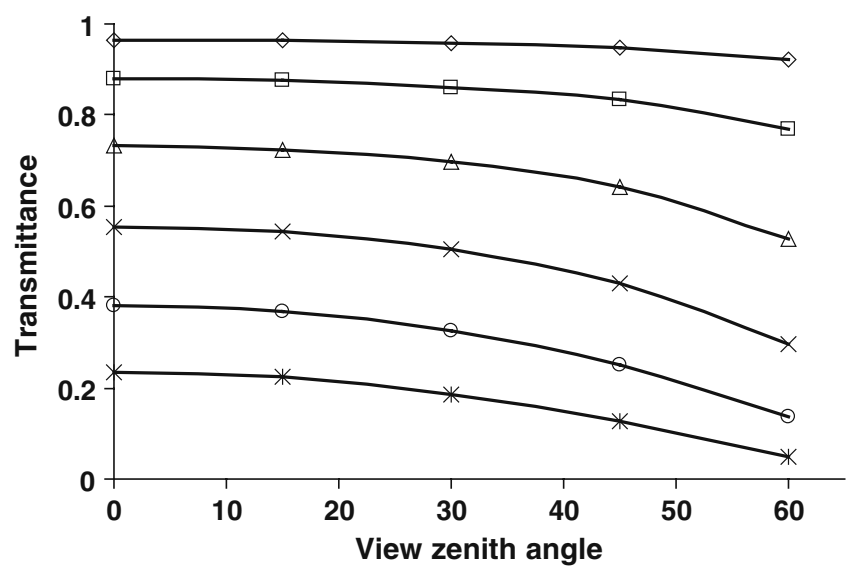

$$
\smile 0.1 \mathrm{~g} / \mathrm{cm}^{2} \longrightarrow-1.5 \mathrm{~g} / \mathrm{cm}^{2} \smile 3.0 \mathrm{~g} / \mathrm{cm}^{2}
$$$$
* 4.5 \mathrm{~g} / \mathrm{cm}^{2} \rightarrow-6.0 \mathrm{~g} / \mathrm{cm}^{2} \rightarrow-7.5 \mathrm{~g} / \mathrm{cm}^{2}
$$

Figure 5. Sensitivity of the atmospheric transmittance as a function of view zenith angle $\left(0\right.$ to $\left.60^{\circ}\right)$ for TIR 1 channel $(10.3-11.3 \mu \mathrm{m})$ in the presence of varying atmospheric water vapour $\left(0.1-7.5 \mathrm{~g} / \mathrm{cm}^{2}\right)$ computed by the MODTRAN model for tropical atmospheric condition for the surface temperature of $305 \mathrm{~K}$.

increases when water vapour amount increases with increasing view angle, i.e., a relative deviation (RD) of $4.46 \%$ at $0.1 \mathrm{~g} / \mathrm{cm}^{2}$, becomes $27.7 \%$ at $3 \mathrm{~g} / \mathrm{cm}^{2}$ and $78.8 \%$ at $7.5 \mathrm{~g} / \mathrm{cm}^{2}$. The varying view zenith angle ultimately influences the atsensor radiances. The effect of view zenith angle on the band-averaged radiance (pertaining to the spectral channel TIR1) for varying LST is shown in figure 6 . The at-sensor radiances reduce with increasing view zenith angle by an amount of 7.33 , 3.41 and $4.32 \%$ (RD) for the LST of 300,305 and $310 \mathrm{~K}$, respectively, corresponding to the case considered for this simulation exercise.

A significant influence of varying atmospheric water vapour content on the at-sensor was observed, which is plotted in figure 7 . The bandaveraged radiance for the TIR 1 channel reduces by an RD of $9.67,11.56$ and $15.48 \%$ for the LST of 300 , 305 and $310 \mathrm{~K}$, respectively. Thus coupled effect of water vapour and view angle becomes quite significant in computing the at-sensor signal. Extensive computations have been carried out for all the spectral channels and for all the model inputs; however, few selected results are presented in this paper.

Forward simulations of satellite level signal for the four thermal infrared channels of the INSAT3D Imager sensor presented in this study are useful in understanding the behaviour of atmosphere as well as land in different channels. It also provides the information about how the at-sensor radiance changes with the different atmospheric conditions either with constant or varied land surface temper-

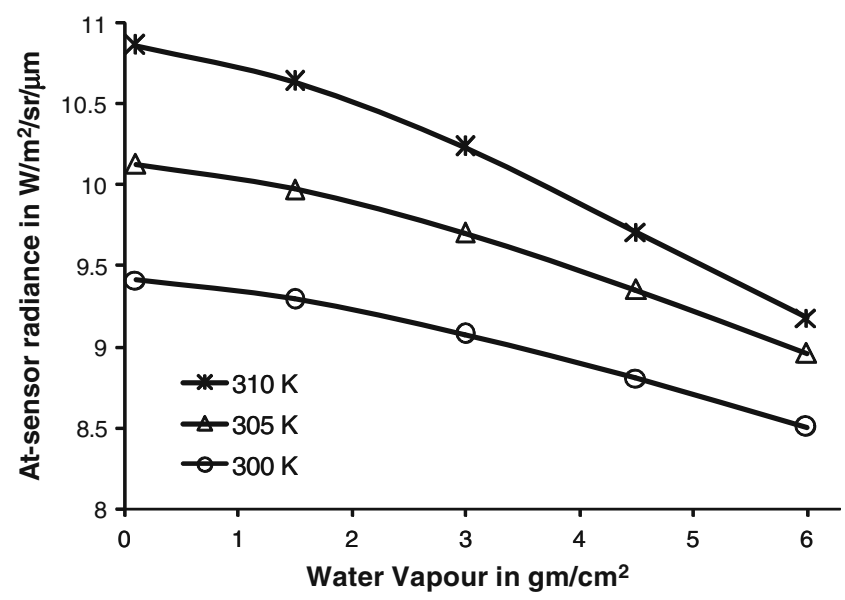

Figure 6. Sensitivity of the at-sensor radiance as a function of view zenith angle $\left(0\right.$ to $\left.60^{\circ}\right)$ for TIR1 channel (10.3$11.3 \mu \mathrm{m})$ over varying $\operatorname{LST}(300-310 \mathrm{~K})$ computed by the MODTRAN model for tropical atmospheric conditions for the atmospheric water vapour of $1.5 \mathrm{~g} / \mathrm{cm}^{2}$.

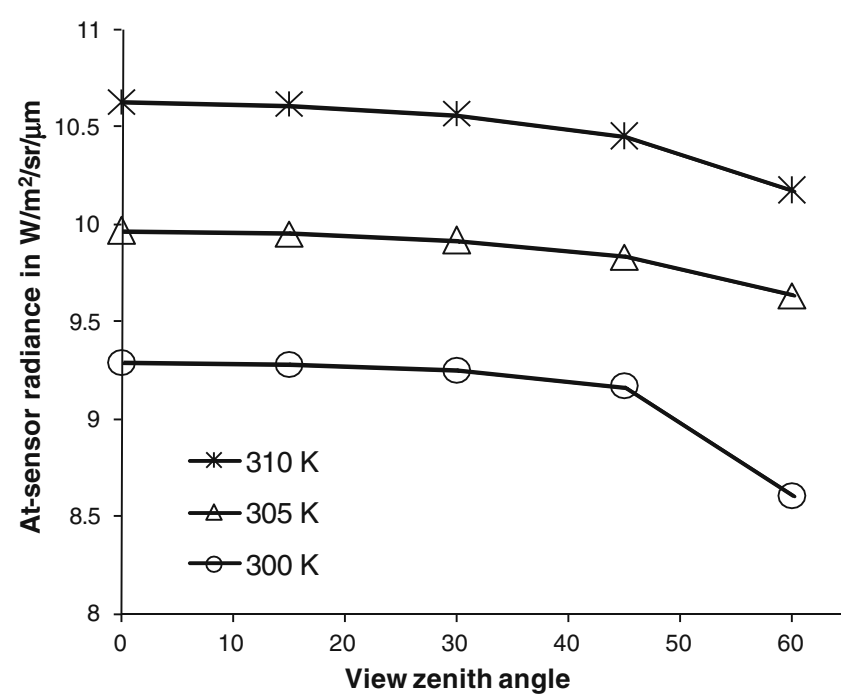

Figure 7. Sensitivity of the at-sensor radiance as a function of atmospheric water vapour $\left(0\right.$ to $\left.6 \mathrm{~g} / \mathrm{cm}^{2}\right)$ for TIR 1 channel (10.3-11.3 $\mu \mathrm{m})$ over varying LST (300-310 K) computed by the MODTRAN model for tropical atmospheric conditions for nadir observations.

atures before the launch of the satellite. Further, these simulations will also be useful in developing the split-window algorithm for land surface temperature retrieval using the split window channels (Wan and Dozier 1996; Sobrino et al 2002; Pandya et al 2010) of the INSAT-3D Imager sensor.

\section{Conclusions}

In this study, a scheme is presented for simulating and understanding the at-sensor radiance in 
four infrared channels of the proposed Imager payload onboard INSAT-3D satellite using the MODTRAN model. Such a scheme is quite useful in understanding the at-sensor signals in the diverse atmosphere-surface scenario before the launch of a satellite (INSAT-3D in this case). The sensitivity of atmospheric transmittance and at-sensor radiance as a function of input parameters such as land surface temperature, atmospheric water vapour, view angle, and emissivity was inferred. A quantification of band-averaged values of at-sensor radiance, transmittance and path radiance is provided for MIR, WVIR, TIR1 and TIR2 channels of the Imager payload in varying atmospheric and surface conditions. A significant coupled effect of atmospheric water vapour and view zenith angle on the atmospheric transmittance and at-sensor radiance was quantified in the four infrared channels of the Imager. A relative deviation of $4.46-78.8 \%$ was observed for a variation of the water vapour content from $0.1-7.5 \mathrm{~g} / \mathrm{cm}^{2}$ and view zenith angle varying from 0 to 60 degrees. A relative deviation of $3.41-15.48 \%$ was observed in the at-sensor radiance for the variation of the water vapour content $\left(0.1-6 \mathrm{~g} / \mathrm{cm}^{2}\right)$ and view zenith angle (0-60 degrees) in the case of LST differing from 300 to $310 \mathrm{~K}$. Results of this study would help in generating a forward simulation scheme for the thermal channels of the Imager payload and ultimately will be useful in developing the split-window coefficients for retrieving an important parameter-land surface temperature from the observations of the Imager payload onboard INSAT-3D satellite. However, the theoretical simulations performed in the study will be improved by incorporating more global atmospheric profiles covering a wide range of variability in water vapour and temperature.

\section{Acknowledgements}

This study is carried out under the SAC R\&D project 'Sensor system studies for the vegetation monitoring'. Authors wish to acknowledge the inspiration and guidance provided by Dr R R Navalgund, Director, SAC; Shri A S Kirankumar,
Associate Director, SAC and Dr J S Parihar, Deputy Director, EPSA/SAC for this study. Discussion and suggestions provided by Dr R P Singh, Scientist, SAC is gratefully acknowledged. Authors thank Dr Basudeb Bakshi, Principal, N. V. Patel College of Pure and Applied Sciences for his encouragement and support.

\section{References}

Borbas E, Seemann S W, Huang H-L, Li J and Menzel W P 2005 Global profile training database for satellite regression retrievals with estimates of skin temperature and emissivity; Proc. Int. ATOVS Study ConferenceXIV, Beijing, China, 25-31 May 2005, pp. 763-770.

CDR 2009 Met Payload Team 'Meteorological payloads: Critical design review document, Imager payload system (vol. 1)'. SAC/SEDA/INSAT-3D/CDR/11/06/0901, June 2009, pp. 376.

Dash P, Göttsche F M, Olesen F S and Fischer H 2002 Land surface temperature and emissivity estimation from passive sensor data: Theory and practice - current trends; Int. J. Remote Sens. 23(13) 2563-2594.

IGBP global land cover; http://www.igbp.net.

Kneizys et al 1988 'Users guide to LOWTRAN 7', Air Force Geophys. Lab., Bedford, MA, Rep. AFGL-TR-88-0177, 1988.

Lacis A A and Oinas V 1991 A description of the correlated $k$ distribution method for modeling nongray gaseous absorption, thermal emission and multiple scattering in vertically inhomogeneous atmospheres; J. Geophys. Res. 96 9027-9063.

Liang S 2004 Quantitative remote sensing of land surfaces; John Wiley \& Sons (USA).

Pandya M R, Shah D B, Trivedi H J and Panigrahy S 2010 Derivation of split window coefficients for retrieving land surface temperature using MODTRAN: The case of MODIS over India; Presented at National Conf. on Climate Change, Indian Society of Geomatics, SAC-ISRO, Ahmedabad, 4-6 February 2010.

Rothman L S et al 1992 The HITRAN molecular database: Editions of 1991 and 1992; J. Quant. Spectrosc. Radiat. Transf. 48469

Sobrino J A, Jimenez J C, Raissouni N and Soria G 2002 A simplified method for estimating the total water vapor content over sea surfaces using NOAA-AVHRR channels 4 and 5. IEEE Trans. Geosci. Remote Sensing $\mathbf{4 0}$ $357-361$.

Wan Z and Dozier J 1996 A generalized split-window algorithm for retrieving land-surface temperature from space. IEEE Trans. Geosci. Remote Sens. 34(4) 892904. 